\title{
Implementing lessons learned from previous bronchial biopsy trials in a new randomized controlled COPD biopsy trial with roflumilast
}

\author{
Neil C Barnes ${ }^{1 *}$, Marina Saetta ${ }^{2}$ and Klaus F Rabe ${ }^{3}$
}

\begin{abstract}
Background: Chronic obstructive pulmonary disease (COPD) is a chronic inflammatory disease mediated by an array of inflammatory cells and mediators, but above all, CD8+ T-lymphocytes, macrophages and neutrophils are important players in disease pathogenesis. Roflumilast, a first-in-class, potent and selective phosphodiesterase 4 (PDE4) inhibitor, reduces the rate of exacerbations in patients with a high risk of future exacerbations and has been shown to reduce inflammatory cells and mediators in induced sputum, a surrogate of airway inflammation. However, these anti-inflammatory effects are yet to be confirmed in another robust study directly assessing inflammatory markers in bronchial sub-mucosa.
\end{abstract}

Methods/Design: An international, 16-week, randomized, double-blind, placebo-controlled, parallel-group study investigating the effects of roflumilast $500 \mathrm{\mu g}$ once-daily versus placebo on inflammatory parameters in bronchial biopsy tissue specimens, sputum and blood serum. One hundred and fifty patients with COPD and chronic bronchitis for at least 12 months will be recruited into the study and randomized in a 1:1 ratio to receive either roflumilast or placebo. The primary endpoint will be the number of CD8+ cells (cell counts per $\mathrm{mm}^{2}$ ) in bronchial biopsy tissue specimens (sub-mucosa) and the key secondary endpoint will be the number of CD68+ cells (cell counts per $\mathrm{mm}^{2}$ ), assessed by indirect immunohistochemistry.

Discussion: It is hypothesized that treatment with roflumilast reduces the characteristic inflammation found in the airways of patients with moderate-to-severe COPD, compared with placebo. The design of the present study has built on the work of previous bronchial biopsy studies available in the literature. It is hoped that it will reveal the cellular mechanisms underlying the anti-inflammatory effects of roflumilast and identify potentially important biomarkers and other surrogate endpoints in patients with COPD. The design and rationale for this trial are described herein.

Trial registration: Clinical trial identifier: NCT01509677 (clinicaltrials.gov)

Keywords: Chronic obstructive pulmonary disease, Roflumilast, Inflammation, Exacerbation, Bronchoscopy, Bronchial biopsy, Protocol, Sputum, Histology

\section{Background}

Chronic obstructive pulmonary disease (COPD) is a major public health problem and it is projected that its burden will increase over the coming decades [1]. The Global Initiative for Chronic Obstructive Lung Disease (GOLD) document defines COPD as a "preventable and treatable disease, characterized by persistent airflow

\footnotetext{
*Correspondence: neil.c.barnes@gsk.com

1 GlaxoSmithKline, Stockley Park West, Uxbridge, Middlesex, UB11 1BT, UK and Barts and The London School of Medicine and Dentistry, London, UK
} Full list of author information is available at the end of the article limitation that is usually progressive and associated with an enhanced chronic inflammatory response in the airways and the lung to noxious particles or gases. Exacerbations and comorbidities contribute to the overall severity in individual patients" [2].

COPD is a chronic inflammatory disease. Most notably, CD8+ T-lymphocytes, macrophages (CD68+) and neutrophils are increased in the airways and sputum of patients with chronic bronchitis and COPD [3-8]. Increased CD8+ T-lymphocyte counts have been characterized in the alveolar walls, [8] pulmonary arteries, [8]

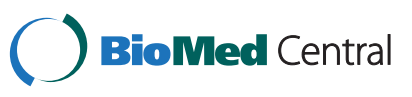


peripheral airways, [3,7] bronchial glands [6] and subepithelium [4] of patients with COPD. Moreover, neutrophil numbers are elevated in the bronchial glands and epithelium, [6] while increased macrophage infiltration has been observed in the subepithelium [4] and bronchial glands of symptomatic patients [6]. In a cross-sectional study of patients with a wide range of COPD severity, Hogg and colleagues have shown that the percentage of airways containing inflammatory cells (including neutrophils, macrophages and CD8+ cells), increases with increasing GOLD stage of COPD [3]. However, the level of inflammation underlies not only disease severity, but also exacerbation severity [9] and recovery time [10]. Papi et al. have observed that the proportion of sputum neutrophilia correlates positively with exacerbation severity, independently of bacterial or viral infections, and that sputum eosinophilia may be a good predictor of an imminent viral exacerbation [9]. There is also a significant relationship between the differences in interleukin (IL)-6 and IL-8 levels at baseline and day 7 after an exacerbation, and symptom recovery time, suggesting an important role of these inflammatory markers [10].

COPD exacerbations are also associated with increased airway and systemic inflammation [11,12]. For example, patients experiencing a severe exacerbation have augmented neutrophilic recruitment and gene expression of neutrophilic chemoattractant proteins compared to controls [11]. IL-6 and IL-8 levels are elevated in the sputum of patients experiencing an exacerbation and even in frequent exacerbators who are stable, [12] while CD8+ T-lymphocytes have been found to be increased at the onset of COPD exacerbations $[13,14]$. Most recently, it has been shown that CD8+ T-lymphocytes actually move from the circulation to the lung following experimental RV infection in COPD patients [15].

The use of bronchial biopsies has contributed significantly to our knowledge of COPD, helping to reveal the anti-inflammatory properties of COPD therapies, and the key role of CD8+ T-lymphocytes in COPD pathology [4,16-18]. One study demonstrated that a salmeterol/fluticasone propionate combination reduces $\mathrm{CD} 8+, \mathrm{CD} 45+$ and CD4+ cell numbers, as well as cells expressing genes for tumor necrosis factor- $\alpha$ (TNF $\alpha)$ [17]. Bourbeau et al. have confirmed that the same combination has antiinflammatory effects which are not observed with use of the inhaled corticosteroid alone [16].

Roflumilast is a first-in-class, potent and selective phosphodiesterase 4 (PDE4) inhibitor, which targets the underlying chronic inflammation in COPD. As the first approved selective PDE4 inhibitor, roflumilast reduces the rate of exacerbations in patients with a high risk of future exacerbations (GOLD patient groups $\mathrm{C}$ and $\mathrm{D}$ ) and symptoms of chronic cough and sputum (chronic bronchitis) $[2,19,20]$. A placebo-controlled clinical study has shown that roflumilast reduces absolute neutrophil and eosinophil counts in induced sputum [21]. However, evidence for its anti-inflammatory effects is limited and warrants further investigation in another study, in patients with COPD.

Accordingly, an ongoing clinical study has been designed with the aim of increasing our understanding of the anti-inflammatory effects of roflumilast. The study will analyze inflammatory markers in bronchial biopsies, induced sputum and blood serum and will offer the opportunity to identify potentially important biomarkers and surrogate endpoints in patients with COPD. The present paper brings the protocol of this clinical study to the attention of the medical community and discusses the rationale behind the study design.

\section{Methods}

\section{Study design}

An international, 16-week, randomized, double-blind, placebo-controlled, parallel group study (Figure 1) investigating the effect of roflumilast $500 \mu \mathrm{g}$ once daily versus placebo on inflammation parameters in bronchial biopsy tissue specimens, sputum and blood serum (clinical trial identifier: NCT01509677). Patients will be equally randomized to either roflumilast treatment or placebo in a 1:1 ratio by means of a computerized central randomization system IVRS/IWRS. The system will assign one or two appropriate trial treatment kit(s) from the stock available at the site for each patient. The primary endpoint of the study will be the number of CD8+ cells (cell counts per $\mathrm{mm}^{2}$ ) in bronchial biopsy tissue specimens (sub-mucosa) evaluated from randomization to the end of the intervention period. The key secondary endpoint will be the number of CD68+ cells (cell counts per $\mathrm{mm}^{2}$ ), assessed over the same timeframe, but a host of other secondary outcomes will also be assessed (Table 1). The study will be conducted at 11 European sites specializing in lung diseases.

\section{Ethical considerations}

This trial will be conducted in accordance with the Declaration of Helsinki, Good Clinical Practice (GCP) guidelines and any additional local regulations. Ethical approval has been gained from the NRES Committee East of England Cambridge South, UK; Regionala etikprövningsnämnden i Lund, Sweden; Komisja Bioetyczna UJ, Poland; EthikKommission der Ärztekammer Schleswig-Holstein (EthikKommission I), Germany as well as the UK, Swedish, Polish and German regulatory agencies.

\section{Patient population}

Patients with a history of COPD for at least 12 months, associated with chronic productive cough for at least three months, in each of the two years prior to baseline visit will be recruited into the study. Patients with moderate-tosevere COPD (stages II and III) will be enrolled (according 


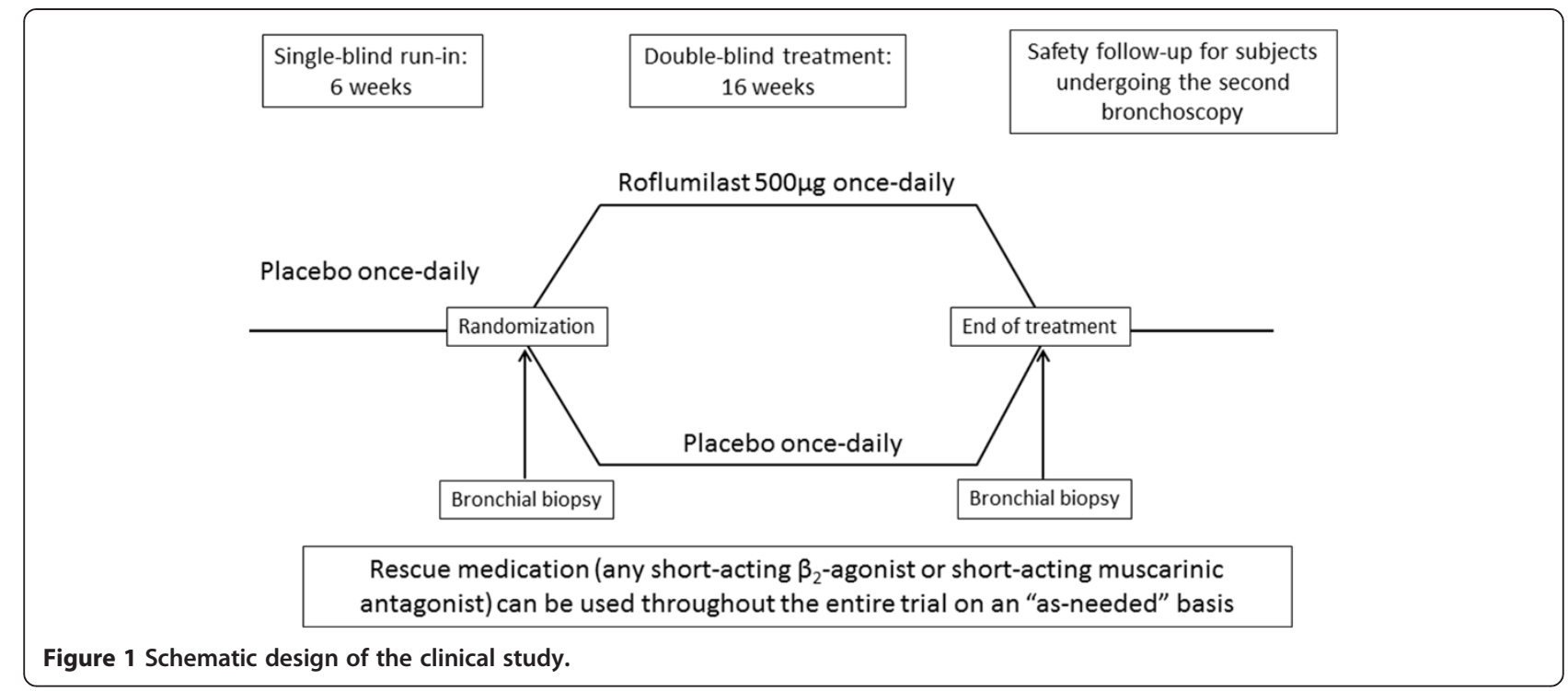

to GOLD 2009). Patients with a history of a recent exacerbation (within six months prior to baseline) will be excluded as will patients who have had a respiratory tract infection, which has not resolved at least four weeks before baseline. Standard bronchodilator therapy use will be permitted throughout the study. However, concomitant medications, including glucocorticoids (inhaled corticosteroids [ICSs]), oral steroids), long-acting $\beta_{2}$ agonist (LABA)/ICS combinations, theophylline, lipoxygenase inhibitors, anti-platelet therapy and leukotriene antagonists will not be permitted throughout the trial and will be withdrawn at the start of the run-in period. Bronchodilators starting at least 6 weeks prior to run-in will be allowed, although these treatments must remain stable throughout the study. Other drugs for the treatment of concurrent disease will be permitted, but their doses must also be kept constant throughout study (including the run-in period). In addition to meeting the admission criteria (Table 2), patients must also satisfy the following conditions in order to be eligible for randomization into the double-blind treatment period:

- No COPD exacerbation between baseline and randomization (as defined by treatment and/or hospitalization)

- Tablet compliance $\geq 80 \%$ and $\leq 125 \%$

Information regarding patients' COPD severity (stage II versus stage III), smoking status, concomitant LABA use and previous inhaled corticosteroid usage will be recorded for the purpose of sub-group analyses and stratification of the most important confounding variables. The number of enrolled patients will be capped at 150 in total.

Roflumilast and placebo tablets will be of identical appearance, shape and colour and will have identical labelling and packaging.

Table 1 Secondary endpoints evaluated from baseline or randomization to the end of the double-blind intervention period

\begin{tabular}{|c|c|c|c|}
\hline Biopsy material & Induced sputum & Blood serum & Pulmonary function changes \\
\hline $\begin{array}{l}\text { Sub-mucosa cell counts } \\
\text { (cells/mm²): CD68+, } \\
\text { Neutrophils, CD4+, } \\
\text { CD45+ }\end{array}$ & $\begin{array}{l}\text { Total and differential cell counts in } \\
\text { induced sputum, absolute (cells/mL) and } \\
\text { percentage (\%): Neutrophils, Macrophages, } \\
\text { Eosinophils, Lymphocytes }\end{array}$ & $\begin{array}{l}\text { Concentration of inflammatory } \\
\text { biomarkers: Inflammatory mediators* } \\
\text { (Human InflammationMAP }{ }^{\circledR} \vee 1.0 ; \\
\text { Myriad RBM) }\end{array}$ & $\begin{array}{l}\text { Change from randomization } \\
\text { to the end of the intervention } \\
\text { period:, FEV } \mathrm{FVC} \mathrm{FEV}_{1} / \mathrm{FVC} \text { ratio }\end{array}$ \\
\hline $\begin{array}{l}\text { Bronchial epithelium } \\
\text { cell counts }\left(\text { cells } / \mathrm{mm}^{2} \text { ): }\right. \\
\text { CD8+ CD68+ }\end{array}$ & $\begin{array}{l}\text { Concentration of inflammatory biomarkers: } \\
\text { Inflammatory mediators* (Human } \\
\text { InflammationMAP }{ }^{\circledR} \vee 1.0 \text {; Myriad RBM) }\end{array}$ & & \\
\hline
\end{tabular}

$\mathrm{FEV}_{1}$ : forced expiratory volume in one second; FVC: forced vital capacity.

*Alpha-1 antitrypsin, alpha-2 macroglobulin, beta-2 microglobulin, brain-derived neurotrophic factor, complement 3, C-reactive protein, eotaxin-1, factor VII, ferritin, fibrinogen, granulocyte-macrophage colony-stimulating factor, haptoglobin, intercellular adhesion molecule-1, interferon gamma, interleukin (IL)-1 alpha, IL-1 beta, IL-1 receptor antagonist, IL-2, IL-3, IL-4, IL-5, IL-6, IL-7, IL-8, IL-10, IL-12 p40, IL-12 p70, IL-15, IL-17, IL-23, macrophage inflammatory protein-1 alpha, macrophage inflammatory protein-1 beta, matrix metalloproteinase (MMP) type 2, MMP type 3, MMP type 9, monocyte chemotactic protein-1, RANTES, stem cell factor, tissue inhibitor of metalloproteinases 1, tumor necrosis factor (TNF)-alpha, TNF-beta, TNF-receptor 2, vascular cell adhesion molecule-1, vascular endothelial growth factor, von Willebrand factor, vitamin D-binding protein. 
Table 2 Main inclusion and exclusion criteria

\begin{tabular}{|c|c|}
\hline Main inclusion criteria & Main exclusion criteria \\
\hline Written informed consent obtained according to local regulations & $\begin{array}{l}\text { Clinical instability (exacerbation } 6 \text { months prior to } \\
\text { baseline as indicated by treatment) }\end{array}$ \\
\hline $\begin{array}{l}\text { History of COPD for at least } 12 \text { months prior to baseline, with chronic productive } \\
\text { cough for at least three months in each of the two years prior to baseline }\end{array}$ & $\begin{array}{l}\text { Upper/lower respiratory tract infection not resolved } 4 \\
\text { weeks prior to baseline }\end{array}$ \\
\hline Outpatients $40-80$ years of age & $\begin{array}{l}\text { Diagnosis of asthma and/or other relevant lung disease } \\
\text { or previous episodes of pneumothorax }\end{array}$ \\
\hline Post-bronchodilator $30 \% \leq \mathrm{FEV}_{1} \leq 80 \%$ predicted & Known alpha-1 antitrypsin deficiency \\
\hline Post-bronchodilator $\mathrm{FEV}_{1} / \mathrm{FVC}$ ratio $\leq 70 \%$ & $\begin{array}{l}\text { History of intubation for COPD or a respiratory failure of } \\
\text { any cause in the past year }\end{array}$ \\
\hline \multirow[t]{2}{*}{ Current or former smokers with smoking history $\geq 20$ pack years } & Formal contraindications to sputum collection \\
\hline & $\begin{array}{l}\text { Suspicion or diagnosis of a bleeding disorder irrespective } \\
\text { of its pathophysiological mechanism }\end{array}$ \\
\hline
\end{tabular}

\section{Sample size}

The sample size of 150 has been calculated from the available information on the primary endpoint and has been kept as small as possible. Previous trials have shown that drop-out rates in bronchial biopsy studies may be as high as $30 \%$ from enrolled patients; $[16,17,22,23]$ therefore, if a conservative estimate of $30 \%$ is applied, the present study may have 105 patients who complete the trial. Drop-outs are difficult to handle in bronchial biopsy studies. If drop-outs are excluded this could unfairly bias the trial, however, if drop-outs continue in the study after having treatment with antibiotics and systemic corticosteroids, this could also bias the results. It is therefore important to choose a group of patients who are unlikely to exacerbate or drop out during the course of the trial, which is the case in our study design. A universally recognized level of clinical relevance regarding the primary endpoint (sub-mucosal CD8+ cells) has not yet been agreed on within the scientific community, but a $30 \%$ improvement using roflumilast treatment over placebo may be of clinical relevance. We have calculated that with a dispersion of 25 , tissue area of $0.3 \mathrm{~mm}^{2}$ and further assumptions (1:1 randomization, two-sided $\alpha=0.05$, power $=0.90$, event rate on roflumilast $=200$ cells $/ \mathrm{mm}^{2}$, event rate on placebo $=285$ cells $/ \mathrm{mm}^{2}$ ), the trial would have a high power (approximately 90\%) to detect treatment differences. However, the study will not be statistically powered to investigate any outcomes with regards to the effectiveness of COPD treatment.

\section{Technical aspects}

\section{Bronchoscopy}

Bronchoscopies will be performed in line with the American Thoracic Society (ATS) guidelines, [24] Endobronchial Biopsy Workshop, [25] modified protocol of O'Shaughnessy et al. [4] and according to local clinical standards of care. Endobronchial biopsies will be taken from each lobar and sub-segmental carina using Olympus EndoJaw single-patient use biopsy cut forceps. In order to take into account both inter and intra-patient variability, 2-3 biopsies will be taken from the lobar bronchus and 2-3 from the sub-segmental airways, at each bronchoscopy session (randomization and end of treatment period). The left and right lobes will be alternated between subjects, but all biopsies will be harvested from the same lung during any given session. The second set of biopsies (after the treatment period) will be taken from the same airway level, but from a different specific site.

In selected patients, three protected brush specimens will be collected during the bronchoscopy procedures. If performed, these specimens will be collected prior to the bronchial biopsy procedure at the same part of the lower lobe bronchus. The specimens will be used to evaluate longitudinal changes in COPD airway microbiota in placebo-treated patients and to define the effect of roflumilast therapy on the airway microbiome.

\section{Biopsy sample processing, cell quantification and biopsy quality}

Biopsies will be gently extracted and sent to the site's laboratory for further processing (fixation and paraffin wax embedding). Immunostaining and quantification of inflammatory cells will be performed according to standard procedures $[4,23,25,26]$. Briefly, inflammatory cells will be identified using indirect immunohistochemistry (using the peroxidase-antiperoxidase complex-PAP- and diaminobenzidine as substrate or the alkaline phosphataseanti-alkaline phosphatase complex; APAAP and Fast Red). For each antibody, the total number of positively stained cells will be counted to a depth of $100 \mu \mathrm{m}$ below the epithelial basement membrane using a computerized image analysis.

To ensure adequate quality and consistency between investigators at different sites, centralized training, covering all aspects of material collection, handling and processing, will be provided. The quality of biopsy material will also be validated for each site, by requesting 
that sites provide pseudonymized samples from the first three enrolled patients. In order to be considered a good quality sample, the biopsied tissue area must be $\geq 0.1 \mathrm{~mm}^{2}$, contain $\geq 1 \mathrm{~mm}$ of basement membrane and be $\geq 100 \mu \mathrm{m}$ deep. Only after the biopsy samples are considered to be of sufficiently good quality will the site be allowed to recruit further patients into the trial.

\section{Inflammatory biomarkers in induced sputum}

Sputum will be induced, collected and initially processed at investigational sites. The quality of sputum samples will also be estimated by investigators on a scale from one to six. Total and differential cell counts of neutrophils, macrophages, eosinophils and lymphocytes will be performed and inflammatory biomarkers will be analyzed using the 46-biomarker Multi-Analyte Profiling (MAP) technology (Human InflammationMAP ${ }^{\ominus}$ v 1.0; Myriad RBM). This tool contains quantitative, multiplexed immunoassays for 46 biomarkers, but the ones of primary interest with regards to this study and roflumilast will be: alpha-2 macroglobulin, interleukin-8 (IL-8), monocyte chemotactic protein-1 (MCP-1), matrix metalloproteinase type 9 (MMP-9), tissue inhibitor of metalloproteinase (TIMP) and vascular endothelial growth factor (VEGF). The remaining 40 biomarkers will only be analyzed exploratively (Table 1). To ensure adequate quality and consistency of samples, centralized hands-on training will be provided and samples will be assessed on an ongoing basis.

\section{Inflammatory biomarkers in blood serum}

Blood withdrawal for the measurement of inflammatory biomarkers will be performed at approximately the same time each day ( \pm 2 hours), but no later than 10:00 am at each respective visit. Inflammatory biomarkers will be quantified using MAP technology (Human InflammationMAP ${ }^{\circledR}$ v 1.0; Myriad RBM).

Blood serum, sputum and biopsy samples will be collected and appropriately stored for up to three years after the end of the study to allow for future analyses of biomarkers of scientific interest.

\section{Pulmonary function tests}

Spirometry will be performed according to the recommendation of the ATS - European Respiratory Society (ATS/ERS) consensus guidelines on pulmonary function testing [27]. Sites will use their own devices, performing maintenance and calibration of instruments according to usual standards of practice. $\mathrm{FEV}_{1}$ (absolute and percentage predicted values), forced vital capacity (FVC) (absolute values) and the ratio of $\mathrm{FEV}_{1} / \mathrm{FVC}$ will also be recorded.

\section{Safety}

Following bronchoscopy with bronchial biopsy, patients will be closely monitored for at least two hours and will only be discharged when the effects of sedation and local anaesthesia disappear as judged by the investigator. All patients will be provided with a 24-hour emergency contact number and a safety follow-up visit will be performed within two weeks after each bronchoscopy session.

\section{Statistical and analytical plans}

The intention-to-treat (ITT) analysis will be based on the full analysis set (FAS). It will be the primary analysis for this study and will be performed for all primary and secondary endpoints. The primary endpoint relates to pulmonary inflammation expressed as CD8+ cell counts per $\mathrm{mm}^{2}$ in sub-mucosal bronchial biopsy tissue specimens measured before and after the double-blind treatment period. The key secondary endpoint relates to CD68+ cell counts per $\mathrm{mm}^{2}$ in sub-mucosal bronchial biopsy tissue specimens. Roflumilast/placebo comparisons for these endpoints will be performed via a multiple test procedure such that the family-wise error rate of $5 \%$ is controlled in the strong sense. The two null hypotheses are: equal $\mathrm{CD} 8+$ counts $/ \mathrm{mm}^{2}$ and equal CD68+ counts $/ \mathrm{mm}^{2}$ for roflumilast and placebo. These null hypotheses will be ordered, so that the CD8+ comparison comes first and the CD68+ comparison comes second. If the comparison with respect to $\mathrm{CD} 8+$ is significant at the nominal level $\alpha=5 \%$, the corresponding null hypothesis will be rejected and the CD68+ comparison will be performed in a confirmatory way (otherwise confirmatory testing stops). This will again be done at nominal level $\alpha=5 \%$. If significant (after a significant result in the first comparison), the corresponding null hypothesis will be rejected. If the first comparison is not significant at 5\% level, then neither null hypothesis must be rejected. The component tests of the multiple test on CD8+ and CD68+ will be based on Poisson regression models with CD8+ $(\mathrm{CD} 68+)$ at end of treatment period as a dependent variable and treatment and baseline values of the respective dependent variable as covariates. A dispersion parameter and an offset (equivalent to the bronchoscopy sampling area) will be taken into account.

Analyses of the other secondary endpoints will be descriptive on treatment and visit, by ANCOVA on absolute change from baseline to last available measurement during double-blind treatment for continuous variables, or Poisson regression for count data. In addition, analyses will be performed in subgroups stratified by COPD stage, smoking status, concomitant LABA and former ICS use.

\section{Discussion}

This clinical study hypothesizes that roflumilast reduces the characteristic inflammation of COPD in patients 
with moderate-to-severe COPD. A specific pattern of inflammation has been characterized in the airways and lung parenchyma of COPD patients, predominantly consisting of increased numbers of CD8+ T-lymphocytes, CD68+ cells and neutrophils [3-8]. Previous research has shown that inflammatory mediators, such as IL-6 and IL-8, also play an important role in COPD [10]. Roflumilast reduces exacerbations in patients with moderate-tosevere COPD and chronic bronchitis, [19] but there are limited clinical data on its anti-inflammatory effects in the lungs as well as systemically [21]. The present study was designed to implement lessons learned from previous bronchial biopsy studies. It will hope to reveal the precise anti-inflammatory properties of roflumilast responsible for its therapeutic effect in the lungs (biopsy and sputum) and identify potentially important biomarkers and surrogate endpoints in patients with COPD. Moreover, the results from this study may also provide a better understanding of the pathophysiology of COPD and serve as a foundation for future research.

\section{Rationale behind the study design}

This will be the first study to associate roflumilast's effects in sputum, the lungs and systemic circulation with observed anti-inflammatory changes. Previous studies have pinpointed CD8+ T-lymphocytes and macrophages $(\mathrm{CD} 68+)$ as cell populations characteristic in COPD inflammation [3-8]. Based on these data, CD8+ and CD68+ cell counts have been selected as the respective key primary and secondary endpoints for this study. The measurement of cell counts per $\mathrm{mm}^{2}$ was selected on the basis that the area profile count is a commonly used method for the quantification of inflammatory cells in bronchial biopsies [16,17,23,28]. Induced sputum offers another opportunity to obtain samples containing potentially valuable information on disease characteristics, relatively easily; while the collection of blood serum for biomarker analyses is based on the hypothesis that systemic inflammation and oxidative stress contribute to the pathogenesis of COPD. It may be argued that the endpoints used in this study are neglecting the most important site of inflammation in COPD - the small airways. However, until safe and reliable methods, which can detect small airway inflammation accurately are developed, the analysis of bronchial biopsies will remain a valuable technique for sampling COPD inflammation.

Roflumilast is effective after only four weeks of treatment, [21] and longer studies have shown similarly consistent clinical improvements [19]. Based on these data and other studies that have revealed anti-inflammatory treatment effects over 3 months, [16,17] a treatment period of 16 weeks has been selected as an optimal length of time to collect information on the anti-inflammatory effects of roflumilast, while allowing sufficient time for patients to fully recover between interventions. A 6-week single-blind run-in period has been incorporated into the study schedule to assess patients' compliance and for reasons of standardization.

Steps have been taken to reduce factors that contribute to intra- and inter-patient variation when obtaining samples. Work by Gamble et al. has shown that endobronchial biopsies from more than one airway generation should be examined in order to maximize statistical power [29]; in this study, 2-3 endobronchial biopsies will be taken from each lobar and sub-segmental carina. At the same time, consistency between investigators and sites will be ensured by way of centralized training. Sites will also be requested to provide biopsy and sputum samples for quality evaluation before they are allowed to enrol further patients.

Selecting the most appropriate patient population for bronchial biopsy studies is an important factor. Ethically, it is not appropriate to subject patients in the indicated roflumilast patient population to the procedures required in this study, since it may put them at increased risk. Furthermore, if patients experience exacerbations during the study and require treatment with steroids or antibiotics, it would confound the analysis of the study and make it difficult to ascertain the effects of roflumilast on inflammation. With this in mind, patients with moderate-to-severe COPD (stages II and III) according to GOLD 2009 were chosen for this study. These patients were considered to be stable enough to be subject to bronchoscopy with bronchial biopsy and sputum collection. Although they are not exactly the indicated roflumilast population, it is important to note that roflumilast improves lung function in patients with stable disease too, regardless of exacerbation history [30,31]. Therefore, the study design provides us with a valuable opportunity to obtain information on the effects of roflumilast in patients with more stable disease, who have not previously been investigated [3]. All patients will continue to receive standard bronchodilator therapy throughout the trial, thereby ethically justifying the placebo arm of the study. Moreover, allowing the use of bronchodilator therapy throughout the trial will also show the effects of roflumilast on top of standard therapy.

The safety of enrolled patients is another important consideration, especially in an invasive study of this kind. Hattotuwa et al. have shown that fibre optic bronchoscopy with bronchial biopsy are procedures that can be performed in research patients with COPD (even with severe disease), with a low incidence of adverse events [32]. Nevertheless, there are risks associated with bronchoscopy such as bleeding, discomfort and coughing, although serious adverse events such as lung leak and pneumothorax are rare [33]. A number of approaches will help to minimize these safety pitfalls in this study. Firstly, bronchoscopies with bronchial biopsies will only 
be conducted at experienced investigational sites, which have demonstrated that they are able to perform these techniques in a standardized and safe manner, in previous clinical studies. Secondly, standardized procedures will be followed by each site. Thirdly, dedicated safety follow-up visits have been included in the study schedule and fourthly, sputum collection will alternate with bronchoscopy visits to limit the number of interventions performed on any given day. Finally, although class-specific adverse events have been reported in previous clinical studies with roflumilast, the treatment has at the same time proved to be effective in COPD patients with moderate-to-very severe airflow limitation $[19,34]$. Nevertheless, drug-specific adverse events will be closely monitored and recorded throughout the study.

\section{Conclusions}

This bronchial biopsy trial will increase our understanding of the anti-inflammatory effects of roflumilast in COPD. Roflumilast reduces COPD exacerbations, but its actions in the lungs, particularly its anti-inflammatory activities, are not well understood. A better comprehension of the effects of roflumilast on inflammatory cells and mediators may help in identifying patients who would benefit most from treatment. It would also improve our understanding of which measurable parameters (e.g. cell counts, activities and mediators) might serve as surrogate predictors for the clinical efficacy of roflumilast.

\begin{abstract}
Abbreviations
APAAP: Alkaline phosphatase-anti-phosphatase complex; ATS: American Thoracic Society; COPD: Chronic obstructive pulmonary disease; ERS: European Respiratory Society; FAS: Full analysis set; FEV ${ }_{1}$ : Forced expiratory volume in one second; FVC: Forced vital capacity; GCP: Good clinical practice; GOLD: Global initiative for chronic obstructive lung disease; ICS: Inhaled corticosteroid; ITT: Intention-to-treat; LABA: Long-acting $\beta_{2}$-agonist; MAP: Multi-analyte profiling; MCP-1: Monocyte chemotactic protein-1; MMP-9: Matrix metalloproteinase-9; PDE4: Phosphodiesterase-4; TFNa: Tumor necrosis factor-alpha; TIMP: Tissue inhibitor of metalloproteinase; VEGF: Vascular endothelial growth factor.
\end{abstract}

\section{Competing interests}

The study is being funded by Takeda Pharmaceuticals International GmbH. N.B. has received lecture and consultancy fees from GlaxoSmithKline, Boehringer Ingelheim, Merck Sharp and Dohme, Nycomed/Takeda, Forest Pharmaceuticals, Almirall and Novartis. He has received research funding from GlaxoSmithKline, AstraZeneca, Almirall and Novartis. At the time of manuscript preparation, N.B. was a Professor of Respiratory Medicine at Barts and The London School of Medicine and Dentistry, UK. He has since moved to GlaxoSmithKline.

M.S. has received lecture fees, consulting fees, and a grant for research from Takeda; has received lecture fees and a grant for research from Chiesi Farmaceutici; and has received lecture fees from GlaxoSmithKline and AstraZeneca. M. Saetta does not have any other competing interests. K.F.R. has provided legal consultation services or expert witness testimony to AstraZeneca, Chiesi Pharmaceutical, Novartis, MSD and GlaxoSmithKline. He has also received research funding from Altana Pharma, Novartis,

AstraZeneca, MSD and Nycomed/Takeda.

\section{Authors' contributions}

All authors are investigators in the study and participated in its design and coordination and helped to draft the manuscript. All authors read and approved the final manuscript.

\section{Acknowledgements}

We thank Alexander Kroll (Senior Medical Writer) at Synergy Vision, UK, for the provision of medical writing, which was funded by Takeda

Pharmaceuticals International $\mathrm{GmbH}$.

\section{Author details}

${ }^{1}$ GlaxoSmithKline, Stockley Park West, Uxbridge, Middlesex, UB11 1BT, UK and Barts and The London School of Medicine and Dentistry, London, UK. ${ }^{2}$ Department of Cardiological, Thoracic and Vascular Sciences, Respiratory Disease Clinics, University of Padova, Via Giustiniani 3, 35128 Padova, Italy. ${ }^{3}$ Department of Medicine, Kiel, Germany and LungenClinic Grosshansdorf, Grosshansdorf, Germany, members of the German Center for Lung Research, University Kiel, Kiel, Germany.

Received: 3 April 2013 Accepted: 24 January 2014

Published: 31 January 2014

\section{References}

1. Lopez AD, Shibuya K, Rao C, Mathers CD, Hansell AL, Held LS, Schmid V, Buist S: Chronic obstructive pulmonary disease: current burden and future projections. Eur Respir J 2006, 27:397-412.

2. Global Initiative for Chronic Obstructive Lung Disease. Global strategy for the diagnosis, management, and prevention of COPD. 2011. Available from: www.goldcopd.org.

3. Hogg JC, Chu F, Utokaparch S, Woods R, Elliott WM, Buzatu L, Cherniack RM, Rogers RM, Sciurba FC, Coxson HO, et al: The nature of small-airway obstruction in chronic obstructive pulmonary disease. N Engl J Med 2004, 350:2645-2653.

4. O'Shaughnessy TC, Ansari TW, Barnes NC, Jeffery PK: Inflammation in bronchial biopsies of subjects with chronic bronchitis: inverse relationship of CD8+ T lymphocytes with FEV1. Am J Respir Crit Care Med 1997, 155:852-857.

5. Lacoste JY, Bousquet J, Chanez P, Van VT, Simony-Lafontaine J, Lequeu N, Vic P, Enander I, Godard P, Michel FB: Eosinophilic and neutrophilic inflammation in asthma, chronic bronchitis, and chronic obstructive pulmonary disease. J Allergy Clin Immunol 1993, 92:537-548.

6. Saetta M, Turato G, Facchini FM, Corbino L, Lucchini RE, Casoni G, Maestrelli P, Mapp CE, Ciaccia A, Fabbri LM: Inflammatory cells in the bronchial glands of smokers with chronic bronchitis. Am J Respir Crit Care Med 1997, 156:1633-1639.

7. Saetta M, Di SA, Turato G, Facchini FM, Corbino L, Mapp CE, Maestrelli P, Ciaccia A, Fabbri LM: CD8+ T-lymphocytes in peripheral airways of smokers with chronic obstructive pulmonary disease. Am J Respir Crit Care Med 1998, 157:822-826.

8. Saetta M, Baraldo S, Corbino L, Turato G, Braccioni F, Rea F, Cavallesco G, Tropeano G, Mapp CE, Maestrelli P, et al: CD8 + ve cells in the lungs of smokers with chronic obstructive pulmonary disease. Am J Respir Crit Care Med 1999, 160:711-717.

9. Papi A, Bellettato CM, Braccioni F, Romagnoli M, Casolari P, Caramori G, Fabbri LM, Johnston SL: Infections and airway inflammation in chronic obstructive pulmonary disease severe exacerbations. Am J Respir Crit Care Med 2006, 173:1114-1121.

10. Perera WR, Hurst JR, Wilkinson TM, Sapsford RJ, Mullerova H, Donaldson GC, Wedzicha JA: Inflammatory changes, recovery and recurrence at COPD exacerbation. Eur Respir J 2007, 29:527-534.

11. Qiu Y, Zhu J, Bandi V, Atmar RL, Hattotuwa K, Guntupalli KK, Jeffery PK: Biopsy neutrophilia, neutrophil chemokine and receptor gene expression in severe exacerbations of chronic obstructive pulmonary disease. Am J Respir Crit Care Med 2003, 168:968-975.

12. Bhowmik A, Seemungal TA, Sapsford RJ, Wedzicha JA: Relation of sputum inflammatory markers to symptoms and lung function changes in COPD exacerbations. Thorax 2000, 55:114-120.

13. Makris D, Lazarou S, Alexandrakis M, Kourelis TV, Tzanakis N, Kyriakou D, Gourgoulianis KI: Tc2 response at the onset of COPD exacerbations. Chest 2008, 134:483-488. 
14. Tsoumakidou M, Tzanakis N, Chrysofakis G, Kyriakou D, Siafakas NM: Changes in sputum T-lymphocyte subpopulations at the onset of severe exacerbations of chronic obstructive pulmonary disease. Respir Med 2005, 99:572-579.

15. Mallia P, Message SD, Contoli M, Gray K, Telcian A, Laza-Stanca V, Papi A, Stanciu LA, Elkin S, Kon OM, et al: Lymphocyte subsets in experimental rhinovirus infection in chronic obstructive pulmonary disease. Respir Med 2013, 108:78-85.

16. Bourbeau J, Christodoulopoulos P, Maltais F, Yamauchi Y, Olivenstein R, Hamid Q: Effect of salmeterol/fluticasone propionate on airway inflammation in COPD: a randomised controlled trial. Thorax 2007 62:938-943

17. Barnes NC, Qiu YS, Pavord ID, Parker D, Davis PA, Zhu J, Johnson M, Thomson NC, Jeffery PK: Antiinflammatory effects of salmeterol/ fluticasone propionate in chronic obstructive lung disease. Am J Respir Crit Care Med 2006, 173:736-743.

18. Lapperre TS, Snoeck-Stroband JB, Gosman MM, Jansen DF, van Schadewijk S, Thiadens HA, Vonk JM, Boezen HM, Ten Hacken NH, Sont JK, et al: Effect of fluticasone with and without salmeterol on pulmonary outcomes in chronic obstructive pulmonary disease: a randomized trial. Ann Intern Med 2009, 151:517-527.

19. Calverley PM, Rabe KF, Goehring UM, Kristiansen S, Fabbri LM, Martinez FJ: Roflumilast in symptomatic chronic obstructive pulmonary disease: two randomised clinical trials. Lancet 2009, 374:685-694.

20. Rennard SI, Calverley PM, Goehring UM, Bredenbroker D, Martinez FJ: Reduction of exacerbations by the PDE4 inhibitor roflumilast-the importance of defining different subsets of patients with COPD. Respir Res 2011, 12:18.

21. Grootendorst DC, Gauw SA, Verhoosel RM, Sterk PJ, Hospers JJ, Bredenbroker D, Bethke TD, Hiemstra PS, Rabe KF: Reduction in sputum neutrophil and eosinophil numbers by the PDE4 inhibitor roflumilast in patients with COPD. Thorax 2007, 62:1081-1087.

22. Hattotuwa K, Gizycki MJ, Ansari TW, Jeffrey PK, Barnes NC: The effects of inhaled fluticasone on airway inflammation in chronic obstructive pulmonary disease. A double-blind, placebo-controlled biopsy study. Am J Respir Crit Care Med 2002, 165:1592-1596.

23. Gamble E, Grootendorst DC, Brightling CE, Troy S, Qiu Y, Zhu J, Parker D, Matin D, Majumdar S, Vignola AM, et al: Antiinflammatory effects of the phosphodiesterase-4 inhibitor cilomilast (Ariflo) in chronic obstructive pulmonary disease. Am J Respir Crit Care Med 2003, 168:976-982.

24. Summary and recommendations of a workshop on the investigative use of fiberoptic bronchoscopy and bronchoalveolar lavage in asthmatics. Am Rev Respir Dis 1985, 132:180-182.

25. Jeffery $P$, Holgate $S$, Wenzel S: Methods for the assessment of endobronchial biopsies in clinical research: application to studies of pathogenesis and the effects of treatment. Am J Respir Crit Care Med 2003, 168:S1-S17.

26. Saetta M, Turato G, Baraldo S, Zanin A, Braccioni F, Mapp CE, Maestrelli P, Cavallesco G, Papi A, Fabbri LM: Goblet cell hyperplasia and epithelial inflammation in peripheral airways of smokers with both symptoms of chronic bronchitis and chronic airflow limitation. Am J Respir Crit Care Med 2000, 161:1016-1021.

27. Miller MR, Hankinson J, Brusasco V, Burgos F, Casaburi R, Coates A, Crapo R, Enright $P$, van der Grinten CP, Gustafsson P, et al: Standardisation of spirometry. Eur Respir J 2005, 26:319-338.

28. Gamble E, Burns W, Zhu J, Ansari T, De RV, Kips J, Barnes NC, Jeffery PK: Variation of CD8+ T-lymphocytes around the bronchial internal perimeter in chronic bronchitis. Eur Respir J 2003, 22:992-995.

29. Gamble E, Qiu Y, Wang D, Zhu J, Vignola AM, Kroegel C, Morell F, Hansel TT, Pavord ID, Rabe KF, et al: Variability of bronchial inflammation in chronic obstructive pulmonary disease: implications for study design. Eur Respir J 2006, 27:293-299.

30. Rabe KF, Bateman ED, O'donnell D, Witte S, Bredenbroker D, Bethke TD: Roflumilast-an oral anti-inflammatory treatment for chronic obstructive pulmonary disease: a randomised controlled trial. Lancet 2005, 366:563-571.

31. Calverley PM, Sanchez-Toril F, Mclvor A, Teichmann P, Bredenbroeker D, Fabbri LM: Effect of 1-year treatment with roflumilast in severe chronic obstructive pulmonary disease. Am J Respir Crit Care Med 2007, 176:154-161.
32. Hattotuwa K, Gamble EA, O'Shaughnessy T, Jeffery PK, Barnes NC: Safety of bronchoscopy, biopsy, and BAL in research patients with COPD. Chest 2002, 122:1909-1912.

33. American Thoracic Society. Fiberoptic bronchoscopy. Patient information series. Am J Respir Crit Care Med 2004, 169:P1-P2.

34. Fabbri LM, Calverley PM, Izquierdo-Alonso JL, Bundschuh DS, Brose M, Martinez FJ, Rabe KF: Roflumilast in moderate-to-severe chronic obstructive pulmonary disease treated with longacting bronchodilators: two randomised clinical trials. Lancet 2009, 374:695-703.

doi:10.1186/1471-2466-14-9

Cite this article as: Barnes et al:: Implementing lessons learned from previous bronchial biopsy trials in a new randomized controlled COPD biopsy trial with roflumilast. BMC Pulmonary Medicine 2014 14:9.

\section{Submit your next manuscript to BioMed Central and take full advantage of:}

- Convenient online submission

- Thorough peer review

- No space constraints or color figure charges

- Immediate publication on acceptance

- Inclusion in PubMed, CAS, Scopus and Google Scholar

- Research which is freely available for redistribution 